\title{
Peripherally inserted central catheter- related bloodstream infection due to Tsukamurella pulmonis: a case report and literature review
}

\author{
Jun Suzuki ${ }^{1}$, Teppei Sasahara ${ }^{1,2^{*}}$, Masaki Toshima ${ }^{1}$ and Yuji Morisawa ${ }^{1}$
}

\begin{abstract}
Background: Tsukamurella pulmonis is an aerobic gram-positive and rod-shaped organism that causes central catheter-related bloodstream infections in immunocompromised hosts. However, peripherally inserted central catheter (PICC)-related bloodstream infections due to this organism have not been reported.

Case presentation: We describe a case of a 48-year-old man with acquired immunodeficiency syndrome and diffuse large B cell lymphoma who received five courses of chemotherapy including rituximab, cyclophosphamide, doxorubicin hydrochloride, vincristine, and prednisone via a PICC. Five days after the last chemotherapy course, he presented with a high fever and shaking chills. His absolute neutrophil count was 4200/uL. Cultures obtained from blood and PICC culture revealed T. pulmonis. The colony count of T. pulmonis grown from PICC culture was $10^{3}$ colony-forming units. Therefore, he was diagnosed with T. pulmonis bacteremia resulting from PICC-related bloodstream infection. The patient's condition improved and he became afebrile within $48 \mathrm{~h}$ after intravenous administration of cefozopran hydrochloride, which is a fourth generation cephalosporin.
\end{abstract}

Conclusions: PICCs can be associated with T. pulmonis bacteremia, and fourth generation cephalosporins may be effective treatment.

Keywords: Tsukamurella pulmonis, Acquired immunodeficiency syndrome (AIDS), Diffuse large B cell lymphoma $(\mathrm{DLBCL})$, Peripherally inserted central catheters (PICCs), Catheter-line associated bloodstream infection (CLABSI)

\section{Background}

Tsukamurella species are aerobic gram-positive and rodshaped organisms with a specific cell wall chemistry that separates them from aerobic actinomycetes [1]. Although infections caused by Tsukamurella species are rare, these species can cause nosocomial infections in immunocompromised hosts [2]. A report from 1996 described isolation of Tsukamurella pulmonis from the sputum of a 92-year-old woman with lung mycobacterium infection [3]. T. pulmonis infections are associated with hematological and immunosuppressed patients, and the reported observations of the infection include

\footnotetext{
* Correspondence: protozoa@jichi.ac.jp

'Division of Infectious Diseases, Jichi Medical University Hospital, 3311-1 Yakushiji, Shimotsuke, Tochigi 329-0498, Japan

${ }^{2}$ Department of Infection and Immunity, School of Medicine, Jichi Medical

University, 3311-1 Yakushiji, Shimotsuke, Tochigi 329-0498, Japan
}

conjunctivitis [4], keratitis [5], pneumonia [6], and central catheter-related bloodstream infections [7].

Peripherally inserted central catheters (PICCs) have been popular because of their safety, easy insertion, and lower rates of infection [8-10]. Although the use of central venous catheters (CVCs) and Hickman catheters is a reported cause of catheter-line associated bloodstream infection (CLABSI) due to T. pulmonis [7], PICC-related bloodstream infections with this organism have not been reported.

Here, we present the case of 48-year-old patient with acquired immunodeficiency syndrome (AIDS) who was diagnosed with PICC-related bloodstream infection due to T. pulmonis. 


\section{Case presentation}

A 48-year-old Japanese man presented with symptoms of right-sided facial asymmetry and right hand palsy that had lasted for 10 days. He had a past medical history of syphilis, gonorrhea, varicella, hepatitis B viral infection, and chronic use of tobacco (1-2 packs of cigarettes per day for 28 years). Laboratory examinations revealed positivity for human immunodeficiency virus (HIV) antigen/antibody, a CD4 positive lymphocyte count of 84 cells/ $\mu \mathrm{L}$, and an HIV-1 RNA viral load of 180,000 copies/mL. Contrast-enhanced magnetic resonance imaging of the head showed three mass lesions in the brain, and the specimen biopsy from these lesions revealed diffuse large B cell lymphoma. He was diagnosed with AIDSassociated primary brain malignant lymphoma. The patient was administered emtricitabine/tenofovir disoproxil combination therapy and raltegravir as the antiretroviral therapy. Atovaquone and azithromycin were also used for prophylaxis of pneumocystis pneumonia and nontuberculous mycobacterial infections.

A PICC was implanted, and he received five courses of R-CHOP chemotherapy (rituximab, cyclophosphamide, doxorubicin hydrochloride, vincristine, and prednisone). Five days after the last R-CHOP chemotherapy course, he suddenly developed a fever with shivering chills. His white blood cell count was $4300 / \mu \mathrm{L}$, and his neutrophil count was $4200 / \mu \mathrm{L}$. The CD4-positive lymphocyte cell count was 228 cells $/ \mu \mathrm{L}$, and the HIV-1 RNA viral load was 20 copies $/ \mathrm{mL}$. We administered $2 \mathrm{~g}$ cefozopran hydrochloride, which is a fourth generation cephalosporin, and vancomycin on day 1 (every $12 \mathrm{~h}$ ) and on day 3, respectively, and the PICC was removed. The patient's condition improved and become afebrile within $48 \mathrm{~h}$ after the initiation of cefozopran hydrochloride. Cultures obtained from blood and revealed grampositive rods, which were identified as T. pulmonis using $16 \mathrm{~S}$ ribosomal RNA gene sequencing. The colony count of $T$. pulmonis grown from PICC culture was $10^{3}$ colony-forming units. Thus, he was diagnosed with $T$. pulmonis bacteremia resulting from a PICC-related bloodstream infection. Because of the results of the susceptibility test (Table 1), we continued cefozopran hydrochloride for 16 days. Follow up blood culture on 5 days after treatment was negative and clinical relapse was not observed. He remains in complete remission as of this report.

\section{Discussion and conclusions}

Although $T$. pulmonis generally causes CLABSI from CVCs and Hickman catheters, we report a case of PICCrelated bloodstream infection due to this microorganism and review the related literature.

Table 2 summarizes the seven reported cases of T. pulmonis bacteremia in the literature $[2,7,11-14]$. Three
Table 1 Minimum inhibitory concentrations (MICs) of the Tsukamurella pulmonis strain in the present case

\begin{tabular}{llll}
\hline Antibiotics & MIC $(\mathrm{mg} / \mathrm{mL})$ & Antibiotics & MIC $(\mathrm{mg} / \mathrm{mL})$ \\
\hline Penicillin G & 8 & Gentamicin & 2 \\
Ampicillin & $\geq 16$ & Amikacin & $\leq 4$ \\
Ceftriaxone & 0.5 & Minomycin & $\leq 0.5$ \\
Cefozopran & 1 & Clindamycin & $\geq 2$ \\
Cefepime & $\leq 1$ & Vancomycin & 2 \\
Imipenem & $\leq 1$ & Levofloxacin & $\leq 0.25$ \\
Meropenem & 0.5 & & \\
\hline
\end{tabular}

patients had severe immunodeficiency combined with bone marrow transplantation, IgA nephropathy, or metastatic breast cancer as the underlying disease [7]. Another three cases had hematological malignancy. One patient had an intracerebral hemorrhage and CLABSI [14]. CVCs or Hickman-catheters were implanted in all of these cases. Therefore, a relationship between CVCs or Hickman-catheters and the presence of T. pulmonis bacteremia exists; however, the risk of $T$. pulmonis bacteremia has not been reported with PICCs.

However, a recent systematic review and meta-analysis showed that the reduced risk of CLABSI with PICCs in comparison to CVCs was greatest for outpatients (RR, 0.22; 95\% CI, 0.18-0.27) than for hospitalized patients (RR 0.73; 95\% CI, 0.54-0.98) and PICC-associated CLABSI occurred as frequently as CVC-associated CLABSI in hospitalized patients (incidence rate ratio 0.91; 95\% CI, 0.46-1.79) [15]. Thus, PICCs may also be a risk factor for CLABSI due to T. pulmonis bacteremia.

The appropriate treatment for T. pulmonis bacteremia remains unknown because standard susceptibility methods for this organism have not been established. There have been a few reports describing various treatments based on susceptibility methods (Table 2), including the E-test using Mueller-Hinton agar plates [13] and the disk diffusion technique [12]. In the present case, minimum inhibitory concentration (MIC) results using the broth dilution method showed susceptibility to vancomycin and cefozopran hydrochloride (Table 1). We continued cefozopran hydrochloride only because of the relatively high MIC for vancomycin. Although further studies are needed to confirm the standard susceptibility methods and optimal susceptibility interpretations, fourth generation cephalosporins including cefozopran hydrochloride and cefepime may be effective against $T$. pulmonis and may represent appropriate treatment for T. pulmonis bacteremia.

The relation between AIDS and the incidence of T. pulmonis bacteremia is unknown. T. pulmonis bacteremia has not been previously reported in AIDS patients, although an advanced-stage AIDS patient with Tsukamurella spp. 
Table 2 Summary of case reports of Tsukamurella pulmonis bacteremia

\begin{tabular}{|c|c|c|c|c|c|c|c|}
\hline $\begin{array}{l}\text { Age } \\
\text { (years) }\end{array}$ & Sex & Diseases & Catheter & Transplantation & Antibiotics & Outcome & Reference \\
\hline 1.5 & M & SCID & Hickman & + & $\begin{array}{l}\text { Amikacin, clarithromycin, ceftriaxone, } \\
\text { vancomycin }\end{array}$ & Survived & [7] \\
\hline 3 & $\mathrm{~F}$ & ALL & CVC & - & $\begin{array}{l}\text { Cefixime, ertapenem, ciprofloxacin, amikacin } \\
\text { oral clarithromycin }\end{array}$ & Survived & [13] \\
\hline 38 & $\mathrm{~F}$ & $\begin{array}{l}\text { High-grade Burkitt-like } \\
\text { lymphoma }\end{array}$ & Hickman & + & Teicoplanin & Survived & [12] \\
\hline 39 & M & ALL & Hickman & No data & Vancomycin, meropenem, amphotericin B & No data & [11] \\
\hline 48 & $\mathrm{~F}$ & IgA nephropathy & CVC & - & Ciprofloxacin, gentamicin, vancomycin & No data & [7] \\
\hline 48 & M & Intracerebral hemorrhage & CVC & - & Ceftazidime, vancomycin & Survived & [14] \\
\hline 67 & $\mathrm{~F}$ & Metastatic breast cancer & CVC & - & Sulfamethoxazole-trimethoprim & No data & [7] \\
\hline
\end{tabular}

SCID severe combined immune deficiency, ALL acute lymphocytic leukemia, CVC central venous catheter

pneumonia was reported by Alcaide et al. [16]. When the CD4-positive lymphocyte cell count is over 200 cells $/ \mu \mathrm{L}$, the defect in cell mediated immunity is mild to moderate, not severe, and it is not clear if this defect is sufficient to explain the predisposition to Tsukamurella infection.

In conclusion, we encountered a case of PICC-related bloodstream infection due to $T$. pulmonis. The present case suggests that PICCs may be a risk factor for developing T. pulmonis bacteremia, and fourth-generation cephalosporins may be effective treatment.

\section{Abbreviations}

AIDS: Acquired Immunodeficiency Syndrome; ALL: Acute lymphocytic leukemia; Cl: confidence interval; CLABSI: catheter-line associated bloodstream infection; DLBCL: diffuse large B cell lymphoma; HIV: human immunodeficiency virus; PICCs: peripherally inserted central catheters; RR: relative risk; SCID: severe combined immune deficiency

\section{Acknowledgements}

Not applicable.

\section{Funding}

All data containing relevant information to support the study findings are included in the manuscript.

\section{Availability of data and materials}

The authors declare that they have no funding for this study.

\section{Authors' contributions}

JS drafted the manuscript. TS helped and revised the manuscript. MT and YM participated in manuscript writing. All authors read and approved the final manuscript.

\section{Ethics approval and consent to participate}

Not applicable.

\section{Consent for publication}

The patient provided informed consent for publication of this report. A copy of written consent is available for review by the Editor of this journal.

\section{Competing interests}

The authors declare that they have no competing interests.

\section{Publisher's Note}

Springer Nature remains neutral with regard to jurisdictional claims in published maps and institutional affiliations.
Received: 12 March 2017 Accepted: 4 October 2017

Published online: 11 October 2017

\section{References}

1. Stackebrandt E, Rainey FA, Ward-Rainey NL. Proposal for a new hierarchic classification system, Actinobacteria classis nov. Int J Syst Evol Microbiol. 1997:47:479-91.

2. Bouza E, Pérez-Parra A, Rosal M, Martín-Rabadán P, Rodríguez-Créixems M, Marín M. Tsukamurella: a cause of catheter-related bloodstream infections. Eur J Clin Microbiol Infect Dis. 2009;28:203-10.

3. Yassin AF, Rainey FA, Brzezinka H, Burghardt J, Rifai M, Seifert P, Feldmann K, Schaal KP. Tsukamurella pulmonis sp. nov. Int J Syst Bacteriol. 1996;46:42936.

4. Woo PC, Ngan AH, Lau SK, Yuen KY. Tsukamurella conjunctivitis: a nove clinical syndrome. J Clin Microbiol. 2003;41:3368-71.

5. Woo PC, Fong AH, Ngan AH, Tam DM, Teng JL, Lau SK, Yuen KY. First report of Tsukamurella keratitis: association between T. Tyrosinosolvens and T. Pulmonis and ophthalmologic infections. J Clin Microbiol. 2009;47:1953-6.

6. Xue XY, Zhou M, Fu WF, Pan YG, Zhao J. Colonic metastasis from primary lung adenocarcinoma: case report and review of the literature. Med Oncol. 2012;29:644-7.

7. Schwartz MA, Tabet SR, Collier AC, Wallis CK, Carlson LC, Nguyen T, Kattar MM, Coyle MB. Central venous catheter-related bacteremia due to Tsukamurella species in the immunocompromised host: a case series and review of the literature. Clin Infect Dis. 2002;35:e72-7.

8. Gunst M, Matsushima K, Vanek S, Gunst R, Shafi S, Frankel H. Peripherally inserted central catheters may lower the incidence of catheter-related blood stream infections in patients in surgical intensive care units. Surg Infect. 2011;12:279-82.

9. Al Raiy B, Fakih MG, Bryan-Nomides N, Hopfner D, Riegel E, Nenninger T, Rey J, Szpunar S, Kale P, Khatib R. Peripherally inserted central venous catheters in the acute care setting: a safe alternative to high-risk short-term central venous catheters. Am J Infect Control. 2010;38:149-53.

10. Kim-Saechao SJ, Almario E, Rubin ZA, Warren DK. Impact of a surgeon-led peripherally inserted central venous catheter team on peripherally inserted central venous catheter-related complications and costs. Surg Infect. 2016: 17:352-6.

11. Shim HE, Sung H, Baek SM, Namgung S, Kim MN, Kim YG, Lee GH. A case of catheter-related bacteremia of Tsukamurella pulmonis. Korean J Lab Med. 2009;29:41-7.

12. Maertens J, Wattiau P, Verhaegen J, Boogaerts M, Verbist L, Wauters G. Catheter-related bacteremia due to Tsukamurella pulmonis. Clin Microbiol Infect. 1998:4:51-3.

13. Pérez Del Molino Bernal IC, Cano ME, García de la Fuente C, MartínezMartínez L, López M, Fernández-Mazarrasa C, Agüero J. Tsukamurella pulmonis bloodstream infection identified by secA1 gene sequencing. J Clin Microbiol. 2015:53:743-5.

14. Cho AR, Kim HR, Lee M-K, Choi SH, Yun SW. A case report of Tsukamurella pulmonis infection misidentified as atypical mycobacteria. Korean J Clin Microbiol. 2010;13:93-7. 
15. Chopra V, O'Horo JC, Rogers MA, Maki DG, Safdar N. The risk of bloodstream infection associated with peripherally inserted central catheters compared with central venous catheters in adults: a systematic review and metaanalysis. Infect Control Hosp Epidemiol. 2013;34:908-18.

16. Alcaide ML, Espinoza L, Abbo L. Cavitary pneumonia secondary to

Tsukamurella in an AIDS patient. First case and a review of the literature. J

Inf Secur. 2004;49:17-9.

Submit your next manuscript to BioMed Central and we will help you at every step:

- We accept pre-submission inquiries

- Our selector tool helps you to find the most relevant journal

- We provide round the clock customer support

- Convenient online submission

- Thorough peer review

- Inclusion in PubMed and all major indexing services

- Maximum visibility for your research

Submit your manuscript at www.biomedcentral.com/submit 